\title{
Surface observation of sand and dust storm in East Asia and its application in CUACE/Dust
}

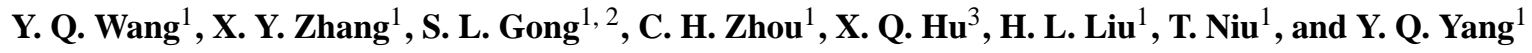 \\ ${ }^{1}$ Laboratory of Atmospheric Chemistry, Centre for Atmosphere Watch and Services, Chinese Academy of Meteorological \\ Sciences, Beijing, China \\ ${ }^{2}$ Air Quality Research Division, Science and Technology Branch, Environment Canada, Toronto, Canada \\ ${ }^{3}$ National Meteorological Satellite Center, CMA, Beijing, China
}

Received: 19 March 2007 - Published in Atmos. Chem. Phys. Discuss.: 27 June 2007

Revised: 20 September 2007 - Accepted: 17 December 2007 - Published: 6 February 2008

\begin{abstract}
The spatial-temporal distributions and sources of sand and dust storm (SDS) in East Asia from 2001 to 2006 were investigated on the basis of visibility and $\mathrm{PM}_{10}$ data from the routine SDS and weather monitoring networks run by CMA (China Meteorological Administration). A power functional relationships between $\mathrm{PM}_{10}$ and visibility was found among various regions generally with a good correlation $\left(r^{2}=0.90\right)$, especially in Asian SDS source regions. In addition, three SDS occurrence centers, i.e. western China, Mongolia and northern China, were identified with the Mongolia source contributing more dust to the downwind areas including Korea and Japan than other two sources. Generally, high $\mathrm{PM}_{10}$ concentrations were observed in most areas of northern China. The highest value was obtained in the center of western China with a spring daily mean value of $876 \mu \mathrm{gm}^{-3}$, and the value in other source regions exceeds $200 \mu \mathrm{gm}^{-3}$. These data sets together with the satellite observations in China form the main observation database for the evaluation and data assimilation of CUACE/Dust system - an operational SDS forecasting system for East Asia.
\end{abstract}

\section{Introduction}

In each spring, the Asian SDS originating from the arid and semi-arid regions of China and Mongolia greatly increases the particulate concentrations locally, regionally and even globally in some events, resulting in significant visibility reduction, respiratory symptoms, eye trouble to human beings as well as damage to animals, plants, industry and social activities (Kim et al., 2001; Seinfeld et al., 2004; Zhang et al., 1993). As one type of severe disaster weather, SDS is a concern of the government and people in China and downwind countries each spring.

Correspondence to: Y. Q. Wang

wangyq@cams.cma.gov.cn
As a natural phenomenon, SDS was recorded in the Diary of Tonghe Weng, indicating an average of over nine dusty days occured annually in Beijing during the period 18601898 AD (Fei et al., 2005). However, systematic monitoring of SDS events was established in China only about half a century ago. As part of the routine weather monitoring network (Fig. 1), atmospheric visibility has been recorded in China from the 1950's to monitor SDS events. The sources, spatial and temporal variation, dust deposition and regional characteristics of SDS have been studied using the visibility dataset (Qian et al., 2004; Sun et al., 2001; Wang et al., 2005; Zhou, 2001; Zhou and Zhang, 2003). A similar dataset was used to investigate SDS characteristics in Mongolia (Natsagdorj et al., 2003). But the above studies did not cover recent years, when significant spatial and temporal variations of SDS were observed. Furthermore, these data are primarily qualitative as only the SDS category was reported. To obtain the dust particle concentrations during SDS events, CMA established a SDS monitoring network with 19 stations located in SDS source and downwind regions in northern China with $\mathrm{PM}_{10}$ (particles with diameter less than $10 \mu \mathrm{m}$ ) observations (Fig. 1) since 2003. Eleven of them are also equipped with instruments to measure visibility.

These two networks provide near real-time distributions of SDS in China for characterizing SDS and model validation. This paper presents the meteorological recorded SDS data in spring from 2001 to $2006, \mathrm{PM}_{10}$ and visibility data at the SDS observation stations in spring from 2004 to 2006. The specific objectives of the studies reported here were to (1) characterize the spatial distribution and temporal variation of the frequency of SDS events in resent years; (2) investigate the $\mathrm{PM}_{10}$ characteristics of northern China in the primary SDS season; (3) find the relationship between $\mathrm{PM}_{10}$ and visibility especially in SDS events; (4) introduce the model verification result based on this dataset.

Finally, these observational data, together with satellite observations (Hu et al., 2007) will facilitate the evaluation

Published by Copernicus Publications on behalf of the European Geosciences Union. 


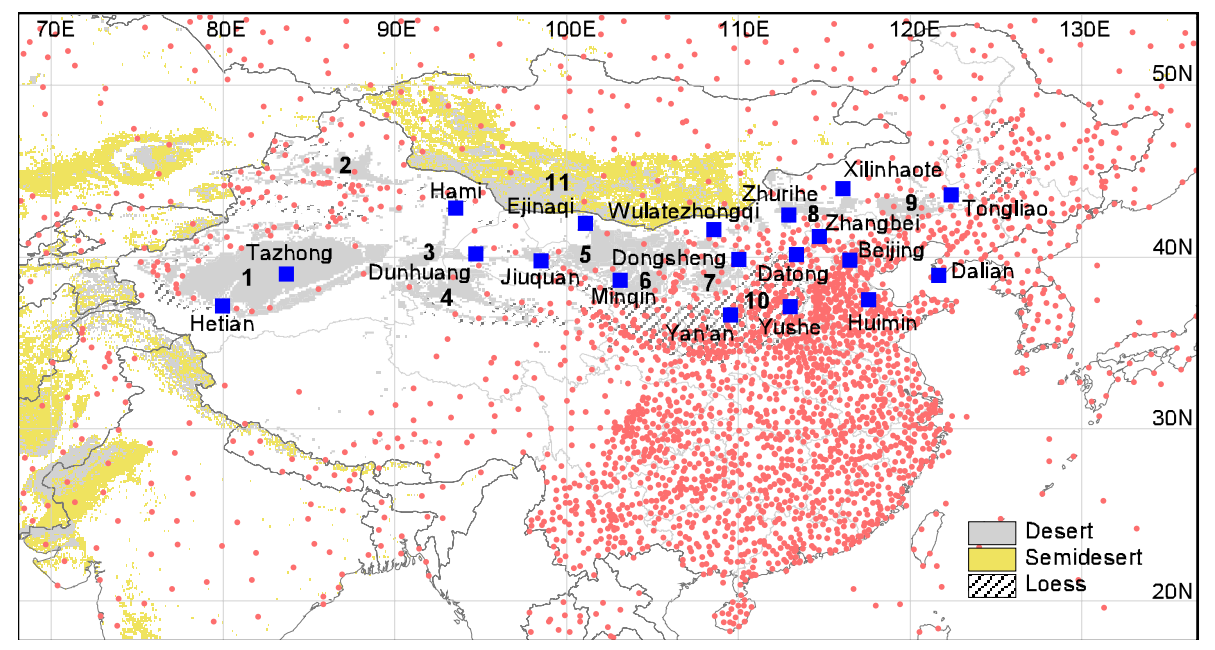

Fig. 1. The distribution map of the stations used to observation SDS in CMA. The red dots are weather stations while the blue squares are SDS observation stations. In this figure, the main SDS source regions are: 1, Taklimakan Desert; 2, Gurbantunggut Desert; 3, Kumtag Desert; 4, Qiadam Basin Desert; 5, Badain Juran Desert; 6, Tengger Desert; 7, Mu Us Desert; 8, Onqin Daga sandy land; 9, Horqin sandy land; 10, Loess Plateau; 11, Deserts and semideserts in Mongolia.

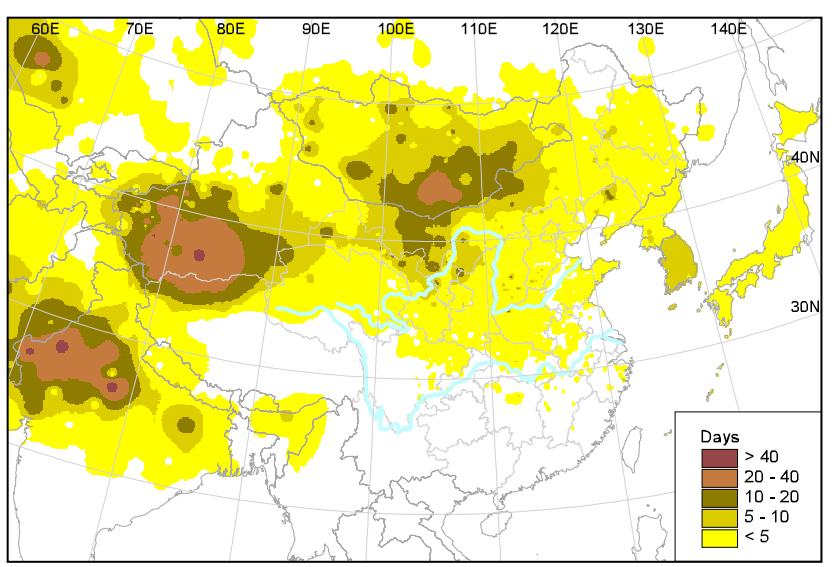

Fig. 2. The distribution of annual mean days of SDS events in spring from 2001 to 2006 .

and data assimilation of the CMA operational SDS forecasting model - CUACE/Dust (China Unified Atmospheric Chemistry Environment for Dust model) (Gong and Zhang, 2007; Zhou et al., 2007) as reported for model improvements and initial forecasting conditions (Niu et al., 2007).

\section{SDS observation data}

\subsection{Meteorological records related to SDS weather}

Figure 1 shows the distribution of the weather stations in China and surrounding countries. Most stations were located in east and south areas of China with high economic development. But, in the Gobi desert and sandy land areas, the sources of SDS, the distribution of the weather stations is very sparse. In the meteorological records of China, four categories of SDS events including suspended dust (horizontal visibility less than $10000 \mathrm{~m}$, and very low wind speed), blowing dust (visibility reduce to $1000-10000 \mathrm{~m}$ ), sand and dust storm (visibility less than $1000 \mathrm{~m}$ ) and severe sand and dust storm (visibility less than $500 \mathrm{~m}$ ) are usually reported in the daily observation. (CMA, 1979). The last three categories of dust events all result from strong winds. Through a data transfer system in CMA, the near real-time SDS observation data with 3-h interval at these stations were obtained. The current weather data in spring from 2001 to 2006 were used in this study.

\section{2 $\mathrm{PM}_{10}$ and visibility data}

The 19 SDS stations with $\mathrm{PM}_{10}$ observation are located in SDS source and downwind regions in northern China (Fig. 1). A Tapered Element Oscillating Microbalance (TEOM, model 1400a, Rupprecht and Patashnick) operated at a controlled flow rate of $4 \mathrm{~L} / \mathrm{min}$ was used to record continuously the $\mathrm{PM}_{10}$ mass concentrations averaged over $5 \mathrm{~min}$ periods in each station. At eleven of the stations 5 min visibilities were also observed automatically on-line using FD12 (Vaisala). After experimental running of the SDS monitoring network in 2003, the $\mathrm{PM}_{10}$ and visibility observation data were started to be transferred to the CMA information center in real-time from 2004. Detailed station information is described in Table 1. 
Table 1. The descriptions of SDS station network in China.

\begin{tabular}{|c|c|c|c|c|c|}
\hline Station & Latitude $\left({ }^{\circ} \mathrm{N}\right)$ & Longitude $\left({ }^{\circ} \mathrm{E}\right)$ & Altitude (m) & Location & Measurement \\
\hline Tazhong & 39.00 & 83.67 & 1099.3 & Center of the Taklimankan Desert & $\mathrm{PM}_{10}$, visibility \\
\hline Hetian & 37.13 & 79.93 & 1374.6 & Southern margin of the Taklimakan Desert & $\mathrm{PM}_{10}$ \\
\hline Hami & 42.82 & 93.52 & 737.2 & Eastern Xinjiang province & $\mathrm{PM}_{10}$, visibility \\
\hline Ejinaqi & 41.95 & 101.07 & 940.5 & Northern margin of the Badain Juran Desert & $\mathrm{PM}_{10}$, visibility \\
\hline Dunhuang & 40.15 & 94.68 & 1139.0 & Eastern margin of the Kumtag Desert & $\mathrm{PM}_{10}$, visibility \\
\hline Jiuquan & 39.77 & 98.48 & 1477.2 & Western margin of the Badain Juran Desert & $\mathrm{PM}_{10}$, visibility \\
\hline Minqin & 38.63 & 103.08 & 1367.0 & Western margin of the Tengger Desert & $\mathrm{PM}_{10}$, visibility \\
\hline Zhurihe & 42.40 & 112.90 & 1150.8 & Southeastern Onqin Dage sandy land & $\mathrm{PM}_{10}$ \\
\hline Wulatezhongqi & 41.57 & 108.52 & 1288.0 & Steppe area in mid-inner Mongolia & $\mathrm{PM}_{10}$, visibility \\
\hline Zhangbei & 41.15 & 114.70 & 1393.3 & Downwind area of east China & $\mathrm{PM}_{10}$, visibility \\
\hline Datong & 40.10 & 113.33 & 1067.2 & Notheastern margin of the Loess Plateau & $\mathrm{PM}_{10}$ \\
\hline Dongsheng & 39.83 & 109.98 & 1460.4 & Notheastern margin of the Mu Us Desert & $\mathrm{PM}_{10}$ \\
\hline Yushe & 37.07 & 112.98 & 1041.4 & Eastern Loess Plateau & $\mathrm{PM}_{10}$, visibility \\
\hline Yan'an & 36.60 & 109.50 & 958.5 & Center of the Loess Plateau & $\mathrm{PM}_{10}$ \\
\hline Xilinhaote & 43.95 & 116.07 & 989.5 & North of Onqin Dage sandy land & $\mathrm{PM}_{10}$, visibility \\
\hline Tongliao & 43.60 & 122.37 & 178.5 & East of Horqin sandy land & $\mathrm{PM}_{10}$ \\
\hline Beijing & 39.80 & 116.47 & 31.3 & Downwind area of east China & $\mathrm{PM}_{10}$ \\
\hline Dalian & 38.90 & 121.63 & 91.5 & Downwind area of east China & $\mathrm{PM}_{10}$ \\
\hline Huimin & 37.48 & 117.53 & 11.7 & Downwind area of east China & $\mathrm{PM}_{10}$ \\
\hline
\end{tabular}

\section{Sand and dust storm occurrences in East Asia}

\subsection{Spatial distribution and sources}

The days of SDS events distinguished from the meteorological records of each weather station in every spring were calculated. Figure 2 shows the distribution of annual mean days of SDS events for all four categories of SDS in spring from 2001 to 2006. There are three SDS centers in East Asia. One is the western China source including the Taklimakan Desert and surrounding area; the other is a Mongolia source including the desert and semi-desert area in southern Mongolia; and the last one is located in northern China, including the Badain Jaran Desert, the Tengger Desert, the Ulan Buh Desert and the Onqin Daga sandy land. Compared with Mongolian sources, northern China has much fewer SDS events in spring, as observed between 2001 and 2006. In a simulation experiment (Zhang et al., 2003), the three centers were also identified as the major Asian dust aerosol sources, with about $70 \%$ dust emission over the past 43 years. Another SDS center is located in northern India and Afghanistan, but it is not an SDS source important to East Asia and will not be discussed further in this paper. Figure 2 shows SDS events observed in Korea, Japan and south of China around the Yangzi River.

The spatial distribution of each SDS type was shown in Fig. 3. Suspended dust events, also called dust fall events, often occurred downwind of SDS with large amounts of dust deposition and very low wind speed. The highest frequency of suspended dust events occurred in the western

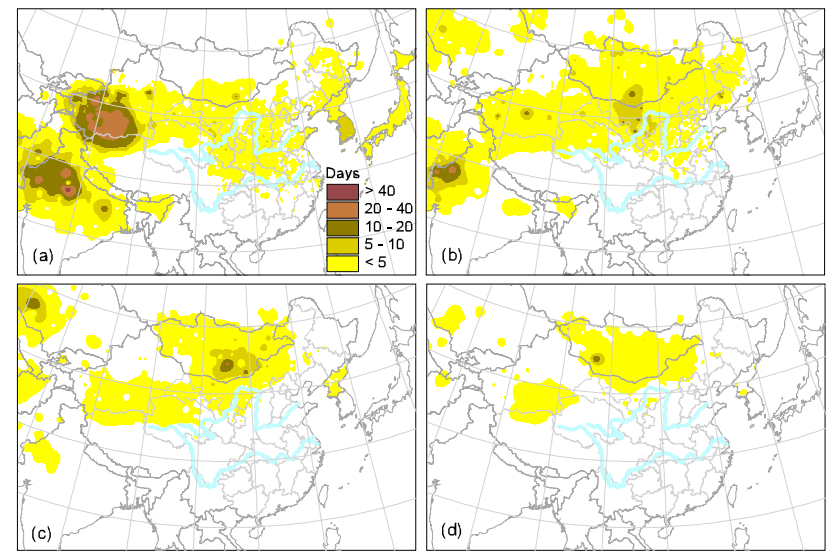

Fig. 3. The distribution of annual mean days of four categories of SDS events in spring from 2001 to 2006. (a) suspended dust; (b) blowing sand; (c) sand and dust storm; (d) severe sand and dust storm.

China source (Fig. 3a), indicating that most of the dust emitted from the Taklimakan Desert were deposited in the desert again. Dust depositions also occurred downwind, covering large areas east and south of China, Korea and Japan. This result is similar to dust deposition flux estimations (Zhang et al., 1998) and a study using data from the period 1960-1999 (Sun et al., 2001). But, frequent suspended dust events were not observed in the Loess Plateau. Both sources in Mongolia and northern China are centers of blowing sand events that influenced all of Mongolia and most of northern China 


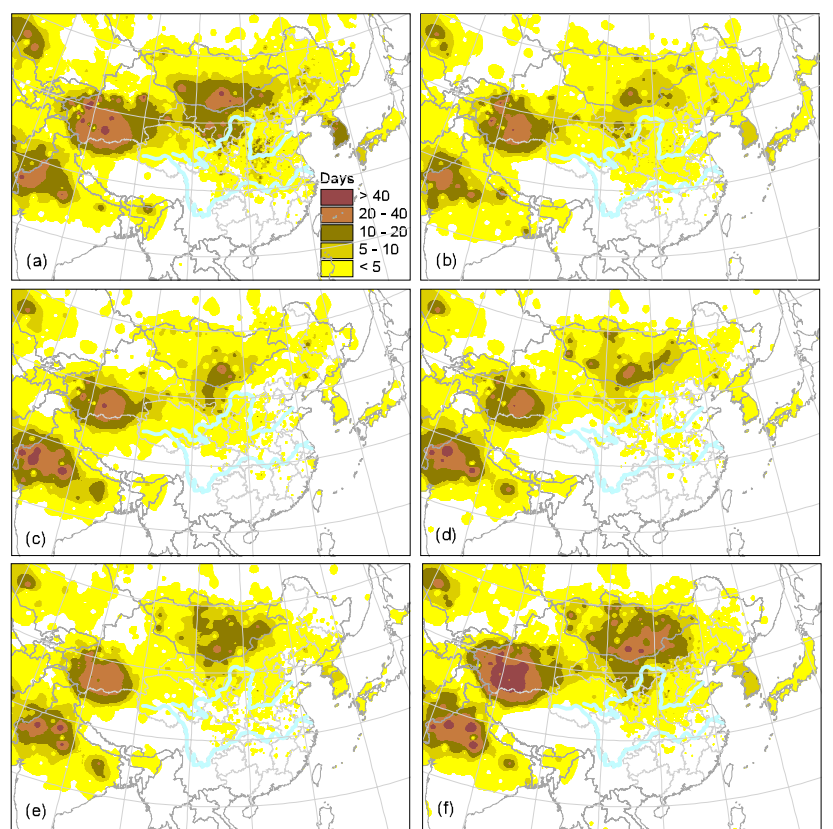

Fig. 4. The distribution of annual mean days of SDS events in spring from 2001 to 2006. (a) 2001; (b) 2002; (c) 2003; (d)2004; (e) 2005; (f) 2006.

(Fig. 3b). In all three SDS sources, SDS and severe SDS events were observed, but the most frequent events occurred in the Mongolia source regions (Fig. 3c and d).

Recent dust deposition data indicate that although many SDS events occurred in the western China source, they contribute little to depositions in the eastern downwind areas including eastern China, Korea and Japan. Most of the dust particles associated with SDS in these areas were mainly from Mongolian and northern China sources in recent years. This is consistent with previous studies using back-trajectory combined $\mathrm{PM}_{10}$ analysis (Wang et al., 2006; Wang et al., 2004) and the study by Sun et al. (Sun et al., 2001). The spatial distribution of SDS event days indicates that the Mongolia source is more important than the northern China source in these years. Zhang et al. (1997) reported that most of dust are transported northerly during relative warm and humid (interglacial) climate conditions, and more dust is delivered northwesterly, when dry and cold (glacial) climates occurred. Based on experimental simulation results, Gong et al. (2004) found that the contributions of surface concentrations from non-Chinese deserts account for up to $60 \%$ in Northeast China and up to $50 \%$ in Korea and Japan.

\subsection{Time series and variation}

From the 1950's when the weather monitoring network of China started to operate, SDS frequency shows a generally descending trend since the early of 1960's in most areas of northern China except in the desertification regions such as the Onqin Daga sandy land (Zhang et al., 2003; Zhou, 2001; Zhou and Zhang, 2003). From 2000 and 2001, the frequency began to rise, reaching a relative peak in 2001, then dropping again in 2002 (Zhang et al., 2003; Zhou and Zhang, 2003). Figure 4 shows the annual variance of SDS occurrence during the springtime 2001-2006. Higher SDS frequency and larger influencing areas were observed in 2001 and 2006 than in the intervening years 2002 through 2005. In the western China source, SDS occurrence is relatively stable during these years, while sharp variance could be seen in both Mongolia and northern China sources. Compared with observations over 1960-1999 (Sun et al., 2001), the SDS center location shifted northward to Mongolia, and the Loess Plateau is no longer a significant deposition region in recent years.

\section{$4 \mathbf{P M}_{10}$ and visibility characteristics}

\section{1 $\mathrm{PM}_{10}$ concentration and visibility measurement results}

The mean daily $\mathrm{PM}_{10}$ concentrations and visibility are shown for each SDS station for all spring data during the period 2004 to 2006 in Fig. 5. The highest $\mathrm{PM}_{10}$ concentrations with mean values of 876 and $703 \mu \mathrm{gm}^{-3}$ were observed at the stations of Tazhong and Hetian which are located in the center and southern margin of the Taklimakan Desert, the western China source for Asian SDS. This is consistent with the frequency of SDS events occurring in this region (Fig. 2). The highest daily averaged $\mathrm{PM}_{10}$ concentration at Tazhong station is $7414 \mu \mathrm{gm}^{-3}$ and the 5 -min data often exceed the upper limit of the instrument of $10000 \mu \mathrm{gm}^{-3}$. At Zhurihe station in Onqin Daga sandy land, in the northeast SDS China source, $\mathrm{PM}_{10}$ concentration is also high with a mean value of $335 \mu \mathrm{gm}^{-3}$. Mean $\mathrm{PM}_{10}$ concentration was observed to exceed $200 \mu \mathrm{gm}^{-3}$ for Minqin, Dongsheng, Datong, Wulatezhongqi, Dunhuang, Ejinaqi and Yushe stations. In Beijing, located in a typical SDS dust transport area, mean $\mathrm{PM}_{10}$

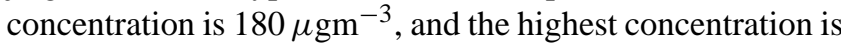
$735 \mu \mathrm{gm}^{-3}$. About half the days in the spring seasons of the three years can be considered polluted, according to $\mathrm{PM}_{10}$ concentrations higher than the Class II Chinese daily $\mathrm{PM}_{10}$ standard of $150 \mu \mathrm{gm}^{-3}$ (GB3095-1996).

Due to the high frequency of SDS events, very low visibility was observed at Tazhong station, with a mean value of $10395 \mathrm{~m}$. However, $\mathrm{PM}_{10}$ concentration and visibility are not linearly correlated in the same manner over all regions in northern China, which is mainly because of different physical and chemical characteristics of the aerosol (Watson, 2002). Yushe is located in a coal enrichment area and infrequently impacted by SDS, its aerosol composition is quite different with Zhurihe located in a SDS source region. This explains the fact that even though Yushe station has an mean daily $\mathrm{PM}_{10}$ concentration of $200 \mu \mathrm{gm}^{-3}$, lower than that at Zhurihe station, Yushe observes a lower visibility than Zhurihe. 


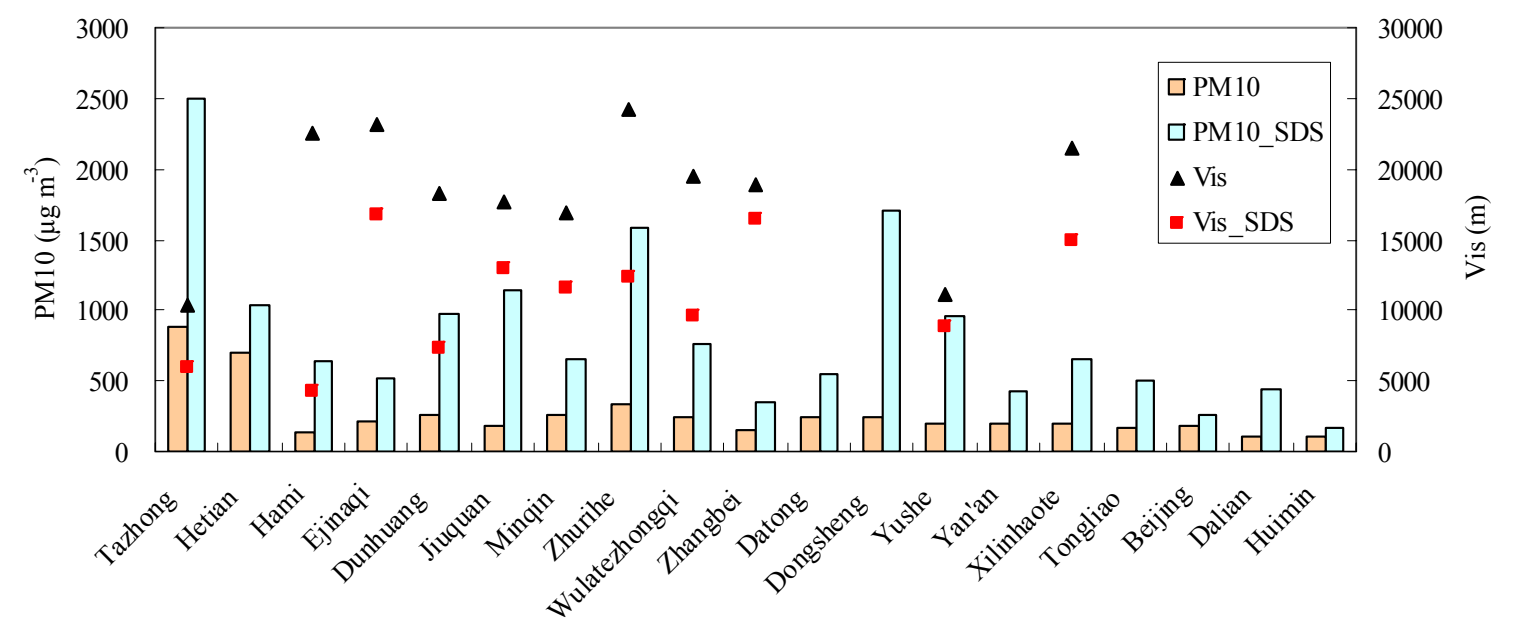

Fig. 5. The daily-averaged mean values of $\mathrm{PM}_{10}$ concentration and visibility of each SDS observation station during the entire period and SDS events period of spring from 2004 to 2006. In the figure, the $\mathrm{PM}_{10}$ mean concentrations for entire period and SDS events period are represented by orange and baby blue bars respectively, while the two kinds of visibility mean values are represented by black triangles and red squares.

Table 2. Observed mean $\mathrm{PM}_{10}$ concentration, visibility based on the data during SDS events and the $\mathrm{PM}_{10}$ concentration values on visibility of $500 \mathrm{~m}, 1000 \mathrm{~m}$ and $10000 \mathrm{~m}$ calculated from the fitting formula.

\begin{tabular}{|c|c|c|c|c|c|c|c|c|}
\hline \multirow[t]{2}{*}{ Data set } & \multirow{2}{*}{$\begin{array}{l}\text { Number of } \\
\text { data pairs }\end{array}$} & \multirow{2}{*}{$\begin{array}{l}\text { Mean } \mathrm{PM}_{10} \\
\left(\mu \mathrm{g} \mathrm{m}^{-3}\right)\end{array}$} & \multirow{2}{*}{$\begin{array}{l}\text { Mean } \\
\text { Visibility (m) }\end{array}$} & \multirow[t]{2}{*}{ Fitting formula } & \multirow[t]{2}{*}{$\mathrm{R}^{2}$} & \multicolumn{3}{|c|}{$\mathrm{PM}_{10}\left(\mu \mathrm{gm}^{-3}\right)$} \\
\hline & & & & & & $\begin{array}{l}\text { Visibility } \\
(500 \mathrm{~m})\end{array}$ & $\begin{array}{l}\text { Visibility } \\
(1000 \mathrm{~m})\end{array}$ & $\begin{array}{l}\text { Visibility } \\
(10000 \mathrm{~m})\end{array}$ \\
\hline Tazhong & 349 & 2493.1 & 5926.2 & $y=8 E+07 x^{-1.3466}$ & 0.8371 & 18563 & 7299 & 329 \\
\hline Ejinaqi & 40 & 514.2 & 16767.8 & $y=8 E+08 x^{-1.6336}$ & 0.8953 & 31193 & 10053 & 234 \\
\hline Dunhuang & 103 & 971.9 & 7331.5 & $\mathrm{y}=5 \mathrm{E}+07 \mathrm{x}^{-1.3088}$ & 0.7593 & 14674 & 5923 & 291 \\
\hline Minqin & 21 & 657.0 & 11637.7 & $y=6 E+08 x^{-1.6097}$ & 0.9108 & 27141 & 8893 & 218 \\
\hline Zhurihe & 37 & 1587.9 & 12404.9 & $y=1 E+08 x^{-1.3687}$ & 0.9138 & 20226 & 7832 & 335 \\
\hline Wulatezhongqi & 19 & 753.8 & 9593.2 & $y=3 E+08 x^{-1.4519}$ & 0.8956 & 36182 & 13226 & 467 \\
\hline Zhangbei & 23 & 348.7 & 16439.5 & $y=8 E+06 x^{-1.1303}$ & 0.6736 & 7119 & 3252 & 241 \\
\hline Xilinhaote & 38 & 652.2 & 14907.2 & $y=1 E+07 x^{-1.1973}$ & 0.6951 & 5868 & 2559 & 162 \\
\hline
\end{tabular}

Generally, SDS events are often associated with much higher mean $\mathrm{PM}_{10}$ concentrations and much lower mean visibility values than the entire period averages for all the stations (Fig. 5). At Tazhong station, the two values are $2493 \mu \mathrm{gm}^{-3}$ and $5926 \mathrm{~m}$ in SDS events. High $\mathrm{PM}_{10}$ concentrations were also observed in Dongsheng and Zhurihe stations with mean value of $1705 \mu \mathrm{gm}^{-3}$ and $1588 \mu \mathrm{gm}^{-3}$ respectively. More obvious increases in $\mathrm{PM}_{10}$ concentrations were observed in Dalian than in Beijing during SDS events.

The annual variation of $\mathrm{PM}_{10}$ concentrations in spring exhibits different patterns in different area (Fig. 6a). In the western China source, $\mathrm{PM}_{10}$ concentrations ranked highest in spring of 2004 at the representative stations of Tazhong and
Hetian, decreased dramatically in 2005, and then increased in spring of 2006. At the other stations near SDS northern China source regions, $\mathrm{PM}_{10}$ concentration reached the highest value in 2006. At stations downwind of SDS areas, the annual variation shows a different pattern than in the source region itself, with relatively higher $\mathrm{PM}_{10}$ concentrations in 2005. Most stations have similar monthly variations of $\mathrm{PM}_{10}$ concentrations, with the highest value in April, except Hetian and Hami with the highest values found in March. This is consistent with the high frequency of SDS that occur in April in east Asia (Sun et al., 2001). 

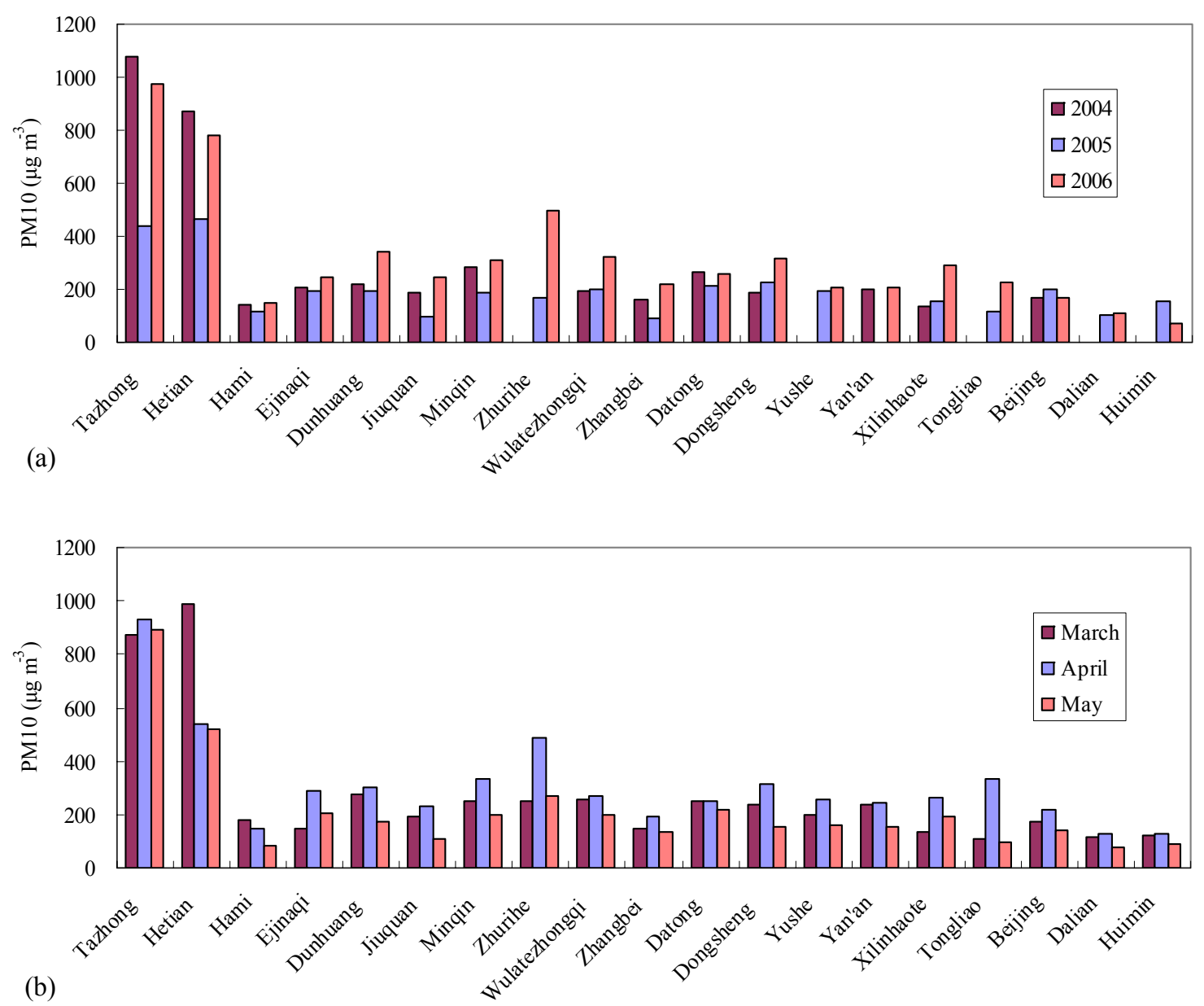

Fig. 6. (a) Annual and (b) monthly mean $\mathrm{PM}_{10}$ mean concentration for each SDS observation station.

4.2 The relationship between $\mathrm{PM}_{10}$ concentration and visibility

Five-minute datasets from typical sites in major sources of Asian SDS were analyzed for hourly $\mathrm{PM}_{10}$ concentrations that compare with corresponding visibility data. The relationships between $\mathrm{PM}_{10}$ and visibility show good correlations $\left(R^{2}\right.$ larger than 0.60$)$ by power function fitting for 3 spring data together at Tazhong, Zhurihe and Minqin, respectively (Fig. 7). At Zhangbei, a station located in a downwind SDS area, the $R^{2}$ decreases to 0.40 , and an even lower $R^{2}$ of 0.22 was found in Yushe station. Yushe was impacted by more anthropogenic aerosols, indicating that mineral aerosol has a better power function relationship with visibility than the mixture of dust and anthropogenic aerosol. This is further illustrated by the same fitting for the data during SDS events only (Fig. 8). The $R^{2}$ reaches about 0.90 at the three SDS stations in source regions, and increases to 0.67 in the downwind station of Zhangbei.

The main model output of CUACE/Dust is dust particle concentration, but visibility is used traditionally to distin- guish the category of SDS. The general public understands "categories" of SDS better than "concentrations" of dust. The three $\mathrm{PM}_{10}$ concentrations corresponding to a visibility of $500 \mathrm{~m}, 1000 \mathrm{~m}$ and $10000 \mathrm{~m}$ were estimated from the data during SDS events (Table 2). The stations of Hami and Yushe were not presented in Table 2, because not enough parallel data were observed during SDS events. The best corresponding $\mathrm{PM}_{10}$ concentrations are found to be 14889,5572 and $213 \mu \mathrm{gm}^{-3}$, respectively. Therefore, the traditional four categories of SDS weather can be divided by hourly PM $_{10}$ concentration ranges as follows:

- Suspended dust: $200 \mu \mathrm{gm}^{-3} \leq \mathrm{PM}_{10}$ (with very low wind speed)

- Blowing dust: $200 \mu \mathrm{gm}^{-3} \leq \mathrm{PM}_{10}<5500 \mu \mathrm{gm}^{-3}$

- Sand and dust storm: $5500 \mu \mathrm{gm}^{-3} \leq \mathrm{PM}_{10}<15000 \mu \mathrm{gm}^{-3}$

- Severe sand and dust storm: $15000 \mu \mathrm{gm}^{-3} \leq \mathrm{PM}_{10}$ 

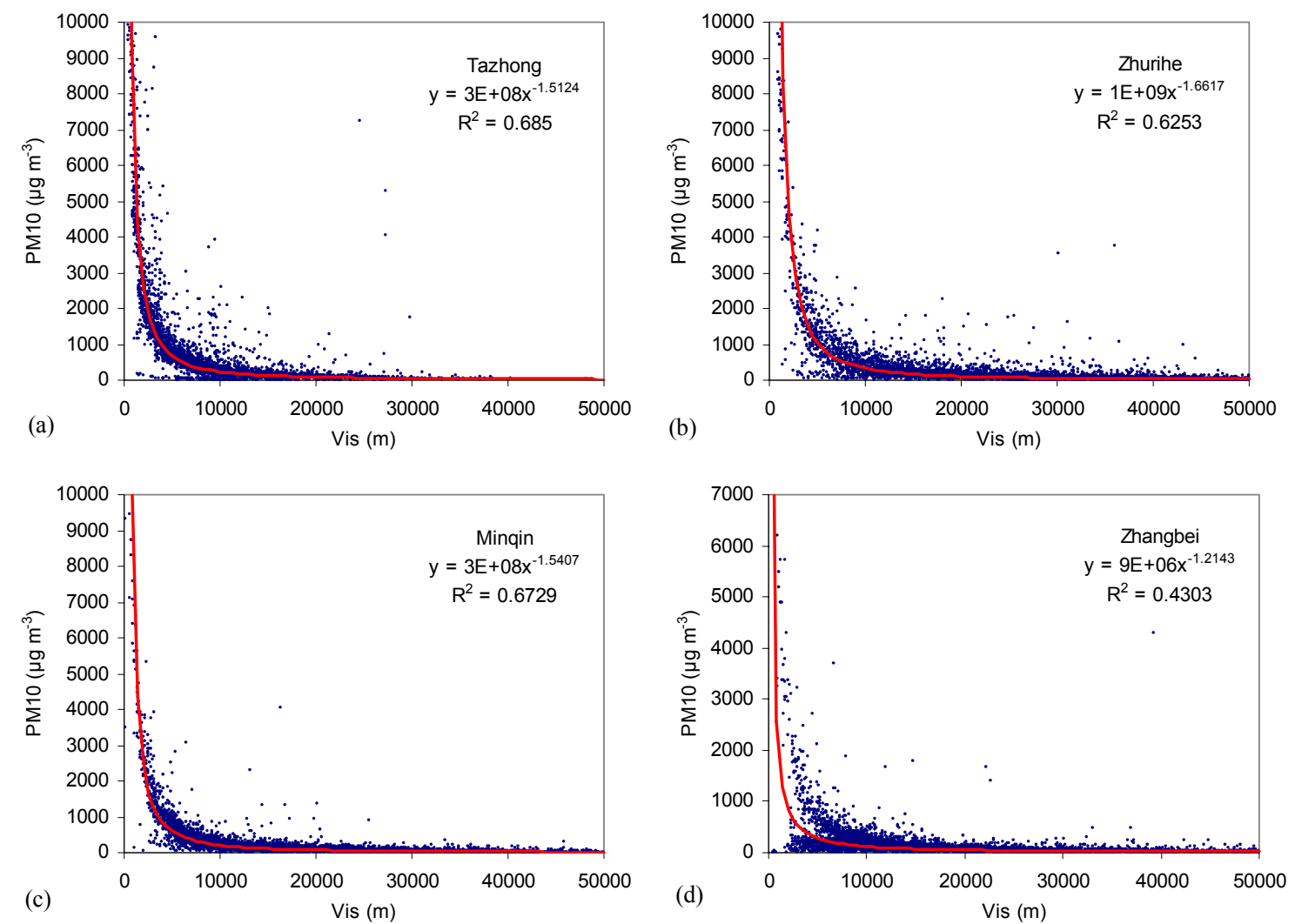

Fig. 7. Plot of hourly-averaged $\mathrm{PM}_{10}$ concentration vs. visibility during 3 spring seasons in the stations of (a) Tazhong, (b) Zhurihe, (c) Minqin and (d) Zhangbei.

\section{Application of observation data in model verification}

Ground-based observations from the two networks and data from FY-2C satellite were assimilated in the CUACE/Dust system to improve its initial SDS condition (Niu et al., 2007). They were also used to verify the SDS forecasts from the modeled concentration of DM40 (dust particle matter with diameter less than $40 \mu \mathrm{m}$ ) (Zhou et al., 2007). This verification shows the model captured the major SDS episodes in 2006 in terms of the particle concentrations and variations at most stations (Zhou et al., 2007). Compared to the weather monitoring network, the measurements made at the SDS stations are more quantitative but limited in spatial coverage (Fig. 1). For spatial verification of the model, the weather monitoring network is used. However, these weather stations represent only a few locations in SDS source regions where most SDS events occur. This disadvantage could be partly overcome by using satellite data.

Grid to grid verification is used in our SDS verification system. Ground-based observation data and the SDS data retrieval from FY-2C satellite were assigned to the grid in areas with no ground station. A GIS (Geographical Information System)-based verification system was developed in ArcView with Avenue language to compare forecasting and observation data on each $1^{\circ} \times 1^{\circ}$ grid.
The method for dichotomous forecast (Wilks, 1995) of SDS and non-SDS was used in this study. As the reference $\mathrm{PM}_{10}$ concentration given above $200 \mu \mathrm{gm}^{-3}$ is the concentration threshold for distinguishing an SDS event from a non-SDS event. The SDS category we used includes all categories of SDS weather from meteorological observations. For satellite observations, it implies that the IDDI index of SDS is higher or equal to 20 (Hu et al., 2007). Treat score (TS), false alarm ratio, miss ratio, accuracy and bias score were calculated from contingency table.

The spatial verification results show that in spring 2006 the daily-averaged TS values are $0.31,0.23$ and 0.21 for $24 \mathrm{~h}$, $48 \mathrm{~h}$ and $72 \mathrm{~h}$ forecasting, respectively. During SDS periods, TS values dramatically increased, with the highest value of 0.63 for $24 \mathrm{~h}$ forecasting on $12 \mathrm{March}$, when a large SDS event occurred. But, on 1 March and 2 March, when no SDS event occurred, TS is 0.00 . The SDS forecasts maintain high accuracy with average value of 0.88 . Verification in different regions indicates the model performs better in western China's Xinjiang province, with an averaged TS value of 0.4 . On each grid, comparison between forecast and observation on each day in spring was also carried out. The temporal verification at each grid was also calculated. Results show that TS is high in the areas around deserts, Gobi deserts and sandy 

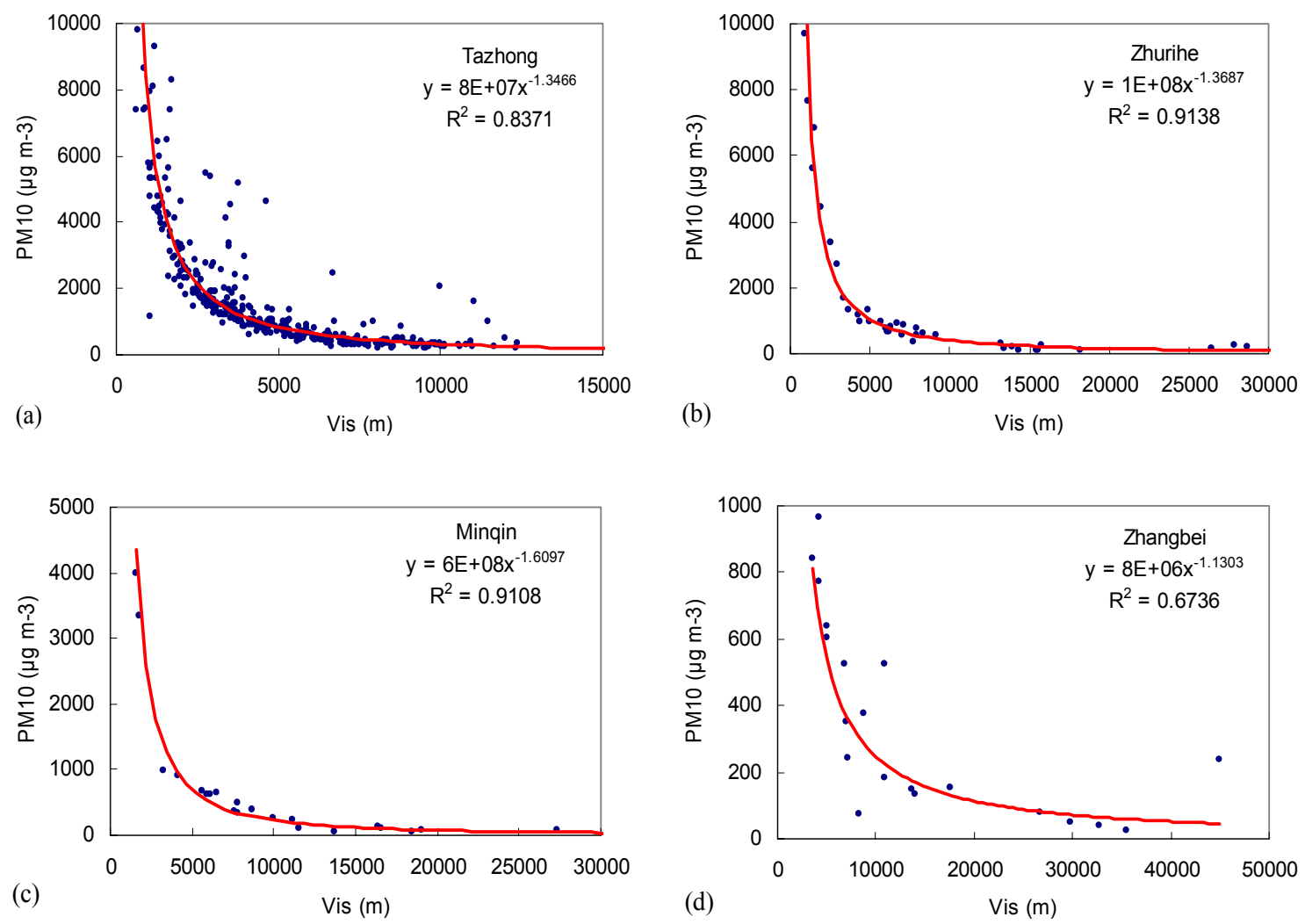

Fig. 8. Plot of hourly-averaged $\mathrm{PM}_{10}$ concentration vs. visibility during SDS events in the springtime in the stations of (a) Tazhong, (b) Zhurihe, (c) Minqin and (d) Zhangbei.

lands that are SDS sources. In most areas, the bias scores are around 1, but in north Xinjing the model often has false positives, or false alarms. North Tibetan and south China are often missed by the forecasting system.

Another version of the model without data assimilation was also run in spring of 2006. Verification results show that without assimilation there is less satisfactory performance in SDS forecasts, with TS of 0.22 for $24 \mathrm{~h}$ forecasting, than if the model is used with data assimilation. A detailed comparison of these results is presented in Niu et al. (2007).

\section{Conclusions}

Investigation of Asian SDS data from meteorological stations over the period 2001 to $2006, \mathrm{PM}_{10}$ and visibility data from the SDS monitoring stations from 2004 to 2006 revealed three high SDS occurrence areas located in western China, Mongolia and northern China. More SDS events occurred in 2001 and 2006, with most strong SDS events occurring in the Mongolia source regions. High $\mathrm{PM}_{10}$ concentrations were always associated with high frequency of SDS events in most areas of northern China. The highest $\mathrm{PM}_{10}$ concentrations were observed in the center of the western China source with mean daily value of $876 \mu \mathrm{gm}^{-3}$. In the eastern part of the northern China source this value is $335 \mu \mathrm{gm}^{-3}$.
Generally in downwind areas, the mean daily $\mathrm{PM}_{10}$ concentration exceeds $100 \mu \mathrm{gm}^{-3}$. The annual variation of $\mathrm{PM}_{10}$ concentration shows different patterns in different regions. The highest monthly mean daily $\mathrm{PM}_{10}$ concentration was observed in April at most SDS stations.

Good correlations are found between $\mathrm{PM}_{10}$ and visibility by power function fitting, especially during SDS events at the source regions. Three reference $\mathrm{PM}_{10}$ values of 200,5500 and $15000 \mu \mathrm{gm}^{-3}$ are estimated to classify the dust concentration from the CUACE/Dust system to the SDS weather categories.

A SDS verification system was also developed based on ground-based observational data supplemented by the SDS data retrieval from FY-2C satellite. TS value of the SDS forecasting from CUACE/Dust system is 0.31 for $24 \mathrm{~h}$ forecasting. The model performs well in SDS forecasting in East Asia, especially during large SDS events. Data assimilation improves model forecasts. 
Acknowledgements. This study was supported by grants from the National Basic Research Program of China (2006CB403701), MOST (2004DIB3J115) and CMA verification project. We are very grateful to W. Sprigg for his comments and the efforts of polishing the English writing of this paper.

Edited by: Y. Balkanski

\section{References}

CMA: Regulations of Surface Meteorological Observation, China Meteorological Press, Beijing, 21-27, 1979.

Fei, J., Zhou, J., Zhang, Q., and Chen, H.: Dust weather records in Beijing during 1860-1898 AD based on the Diary of Tonghe Weng, Atmos. Environ., 39, 3943-3946, 2005.

Gong, S. L. and Zhang, X. Y.: CUACE/Dust - an integrated system of observation and modeling systems for operational dust forecasting system in Asia, Atmos. Chem. Phys. Discuss., 7, $10323-$ 10342, 2007.

Gong, S. L., Zhang, X. Y., Zhao, T. L., and Barrie, L. A.: Sensitivity of Asian dust storm to natural and anthropogenic factors, Geophys. Res. Lett., 31, L07210, doi:10.1029/2004GL019502, 2004.

Hu, X. Q., Lu, N. M., Niu, T., and Zhang, P.: Operational retrieval of Asian sand and dust storm from FY-2C geostationary meteorological satellite and its Application to real time Forecast in Asia, Atmos. Chem. Phys. Discuss., 7, 8395-8421, 2007, http://www.atmos-chem-phys-discuss.net/7/8395/2007/.

Kim, K. W., Kim, Y. J., and Oh, S. J.: Visibility impairment during Yellow Sand periods in the urban atmophere of Kwangju, Korea, Atmos. Environ., 35, 5157-5167, 2001.

Natsagdorj, L., Jugder, D. and Chung, Y. S.: Analysis of dust storms observed in Mongolia during 1937-1999, Atmos. Environ., 37, 1401-1411, 2003.

Niu, T., Gong, S. L., Zhu, G. F., Liu, H. L., Hu, X. Q., Zhou, C. H., and Wang, Y. Q.: Data assimilation of dust aerosol observations for CUAES/Dust forecasting system, Atmos. Chem. Phys. Discuss., 7, 8309-8332, 2007, http://www.atmos-chem-phys-discuss.net/7/8309/2007/.

Qian, W. H., Tang, X. and Quan, L. S.: Regional characteristics of dust storms in China, Atmos. Environ., 38, 4895-4907, 2004.

Seinfeld, J. H., Carmichael, G. R., Arimoto, R., Conant, W. C., Brechtel, F. J., Bates, T. S., Cahill, T. A., Clarke, A. D., Doherty, S. J., Flatau, P. J., Huebert, B. J., Kim, J., Markowicz, K. M., Quinn, P. K., Russell, L. M., Russell, P. B., Shimizu, A., Shinozuka, Y., Song, C. H., Tang, Y. H., Uno, I., Vogelmann, A. M., Weber, R. J., Woo, J. H., and Zhang, X. Y.: ACE-ASIA - Regional climatic and atmospheric chemical effects of Asian dust and pollution, B. Am. Meteorol. Soc., 85, 367-380, 2004.
Sun, J., Zhang, M., and Liu, T.: Spatial and temporal characteristics of dust storms in China and its surrounding regions, 1960 1999: Relations to source area and climate, J. Geophys. Res., 106, 10325-10333, 2001.

Wang, S., Wang, J., Zhou, Z., and Shang, K.: Regional characteristics of three kinds of dust storm events in China, Atmos. Environ., 39, 509-520, 2005.

Wang, Y. Q., Zhang, X. Y., and Arimoto, R.: The Contribution from Distant Dust Sources to the Atmospheric Particulate Matter Loadings at XiAn, China during Spring, Sci. Total Environ., 368, 875-883, 2006.

Wang, Y. Q., Zhang, X. Y., Arimoto, R., Cao, J. J., and Shen, Z. $\mathrm{X}$.: The transport pathways and sources of $\mathrm{PM}_{10}$ pollution in Beijing during spring 2001, 2002 and 2003, Geophys. Res. Lett., 31, L14110, doi:10.1029/2004GL019732, 2004.

Watson, J.: Visibility: Science and Regulation, J. Air Waste Manage., 52, 628-713, 2002.

Wilks, D. S.: Statistical Methods in the Atmospheric Sciences, Academic Press, San Diego, 1995.

Yang, Y. Q., Zhou, C. H., Liu, H. L., Wang, Y. Q., and Niu, T.: Sand/dust storm processes in Northeast Asia and associated large-scale circulation., Atmos. Chem. Phys., 8, 25-33, 2007, http://www.atmos-chem-phys.net/8/25/2007/.

Zhang, X. Y., Arimoto, R., and An, Z. S.: Dust emission from Chinese desert sources linked to variations in atmospheric circulation, J. Geophys. Res., 102, 28 041-28 047, 1997.

Zhang, X. Y., Arimoto, R., An, Z. S., Chen, T., Zhang, G. Y., Zhu, G. H., and Wang, X. F.: Atmospheric trace elements over source regions for Chinese dust: Concentrations, sources and atmospheric deposition on the Loess Plateau, Atmos. Environ., 27, 2051-2067, 1993.

Zhang, X. Y., Arimoto, R., Zhu, G. H., Chen, T., and Zhang, G. Y.: Concentration, size-distribution and deposition of mineral aerosol over Chinese desert regions, Tellus, 50B, 317-330, 1998.

Zhang, X. Y., Gong, S. L., Zhao, T. L., Arimoto, R., Wang, Y. Q., and Zhou, Z. J.: Sources of Asian dust and role of climate change versus desertification in Asian dust emission, Geophys. Res. Lett., 30, 2272, doi:10.1029/2003GL018206, 2003.

Zhou, C. H., Gong, S. L., Zhang, X. Y., Wang, Y. Q., Niu, T., Liu, H. L., Zhao, T. L., Yang, Y. Q., and Hou, Q.: Development and evaluation of an operational SDS forecasting system for East Asia: CUACE/Dust, Atmos. Chem. Phys. Discuss., 7, 7987-8015, 2007, http://www.atmos-chem-phys-discuss.net/7/7987/2007/.

Zhou, Z. J.: Blowing-sand and sandstorm in China in recent 45 years, Quaternary Sciences, 21, 9-17 (in Chinese), 2001.

Zhou, Z. J. and Zhang, G. C.: Typical severe dust storms in northern China during 1954-2002, Chinese Sci. Bull., 48, 2366-2370, 2003. 